\title{
Avaliação da gestão organizacional em cooperativas de agricultores familiares do estado do Paraná
}

\author{
Marcos Roberto Pires GREGOLIN ${ }^{1 *}$, Graciela Caroline GREGOLIN ${ }^{2}$, Vinicius MATTIA ${ }^{3}$, \\ Fábio CORBARI ${ }^{3}$, Wilson João ZONIN ${ }^{3}$
}
${ }^{1}$ Graduando em Gestão do Agronegócio e Doutorando em Extensão Rural, Universidade Federa de Santa Maria, Santa Maria, RS, Brasil.
${ }^{2}$ Faculdade de Pato Branco, Pato Branco, PR, Brasil.
${ }^{3}$ Centro de Ciências Agrárias, Universidade Estadual do Oeste do Paraná, Marechal Candido Rondon, PR, Brasil. *E-Mail: marcosgregolin@yahoo.com.br

Recebido em dezembro/2017; Aceito em junho/2018.

\begin{abstract}
RESUMO: A presente pesquisa desenvolveu-se no âmbito do Projeto Ater "Mais Gestão", proposto pelo Ministério do Desenvolvimento Agrário - MDA e teve como objetivo analisar o diagnóstico de 25 cooperativas da agricultura familiar localizadas no estado do Paraná. Optou-se pela análise minuciosa da área de Gestão Organizacional, pois constatou-se em estudos preliminares que esta subárea apresentou as maiores fragilidades. Tratou-se de um estudo documental, observacional e bibliográfico. Constatou-se que os principais limites se encontram nas subáreas "estrutura organizacional" e "organização do quadro social”, e as potencialidades nas subáreas "direção e participação" e "organização do quadro social”. Pondera-se também que os principais fatores que interferem na gestão organizacional das cooperativas da agricultura familiar incluem o apoio estatal, a escolha dos cooperados, a participação efetiva dos membros nas decisões e na gestão e o acesso às tecnologias, crédito e mercado.
\end{abstract}

Palavras-chave: desenvolvimento, cooperativismo, economia solidária.

\section{Evaluation of Organizational Management in Cooperatives of Family Farmers of the State of Paraná}

\begin{abstract}
The present research was developed in the scope of the Ater Project "More Management", proposed by the Ministry of Agrarian Development - MAD and had the objective of analyzing the diagnosis of 25 family farming cooperatives located in the state of Paraná. It was opted for the detailed analysis of the Organizational Management area, because in preliminary studies this subarea presented the greatest weaknesses. It was a documentary, observational and bibliographic study. It was found that the main limits are in the subareas "organizational structure" and "organization of the membership", and the potentialities in the subareas "direction and participation" and "organization of membership". The main factors that interfere in the organizational management of family farming cooperatives include state support, cooperative choice, effective participation of members in decision-making and management, and access to technologies, credit, and the market. Keywords: development, cooperativism, solidarity economy.
\end{abstract}

\section{INTRODUÇÃO}

Este trabalho tem por escopo a análise documental de diagnósticos realizados durante a operacionalização do Projeto "Mais Gestão" em 25 cooperativas do estado do Paraná. O projeto de Ater "Mais Gestão", proposto pelo Ministério do Desenvolvimento Agrário - MDA, se caracteriza como uma iniciativa pioneira no âmbito da Assistência Técnica e Extensão Rural (Ater), haja vista que direciona o seu foco de atuação para as organizações da agricultura familiar. Este direcionamento se deve ao fato do reconhecimento de que um grande gargalo para a inserção da produção dos agricultores familiares nos mercados está na fragilidade de suas organizações econômicas.

$\mathrm{O}$ formulário de diagnóstico se constitui de seis áreas ${ }^{\mathrm{i}} \mathrm{e}$ trinta subáreas. Trata-se de um formulário com 260 questões fechadas para as quais se admitia as seguintes respostas: Sim, Não, Parcial e Não se aplicaii. Cada uma das questões revelou a opinião dos cooperados sobre o status do assunto abordado na entrevista, e no conjunto das questões por subárea deu-se a atribuição dos conceitos muito bom, bom e ruim.
Tendo por base uma análise preliminar dos dados, constatou-se que o maior gargalo paira sob a área Gestão Organizacional, pois, em $76 \%$ das cooperativas, a estrutura organizacional encontra-se com desempenho ruim ${ }^{\mathrm{iii}}$. Ademais, nota-se que, nessa subárea, em nenhuma das cooperativas tratadas o desempenho muito bom foi constatado. Diante disto, neste trabalho ocupou-se em abordar a primeira área do diagnóstico, "Gestão Organizacional", contudo, outras leituras e percepções podem sugerir que todas as áreas e subáreas possuem respaldo e importância, todavia, em se tratando de que toda a pesquisa se reveste de uma escolha, para este trabalho, optou-se por tal percepção, tendo os argumentos já apresentados como justificativa e também o exposto por Sachs (2008)

O aperfeiçoamento organizacional é tão importante quanto o aperfeiçoamento técnico. Os pequenos produtores em via de transformação em pequenos empresários precisam melhorar a sua cultura administrativa. Ao mesmo tempo, deve-se ajudá-los a tirar proveito da assistência mútua e do empreendedorismo coletivo, como meios poderosos de fortalecer os seus esforços individuais. (SACHS, 2008, p. 52) 
Motivou a realização deste estudo a necessidade de se conhecer o status da gestão das cooperativas, as peculiaridades da gestão organizacional bem como as potencialidades e fragilidades presentes nessa área.

\section{MATERIAL E MÉTODOS}

Metodologicamente este trabalho se caracteriza como um estudo documental, pois busca em fontes, sistematizadas ou não, informações para poder alimentar a discussão que se propõem. Também se valeu da observação participante artificial, haja vista que um dos autores atuou como técnico nas cooperativas durante o período de 2013 a 2016. Tendo em vista que uma pesquisa não nasce isolada de outros estudos, buscou-se por meio da revisão bibliográfica elementos que conduzissem o trabalho em autores como Singer (2008; 2013), Sen (2010) e Sachs $(2003 ; 2009)$. Como referências também se utilizou os conceitos e discussões de Asaf Neto (2007), Bialoskorski Neto (2006), Bilibio (2009), BRASIL (1971), Chiavenato (2003), Desroche (2006), Dias (2002), Hunter (2000), Ignácio (2008), Lago (2009), Maximiano (2000), Proença (2009) e Scorsolini-Comin (2012).

Sobre pesquisa documental diz-se que nelas são utilizados documentos cujas informações ainda não foram tratadas, ou como neste caso informações "que ainda podem ser reelaborados de acordo com os objetivos da pesquisa" (GIL, 2008, p. 51), sobre a revisão bibliográfica o mesmo autor infere que é uma etapa muito importante das pesquisas, haja vista que permite conhecer os fatos e as interpretações dadas por diversos autores sobre o tema em questão. Sobre a observação salienta-se que "nada mais é que o uso dos sentidos com vistas a adquirir os conhecimentos necessários para o cotidiano" (GIL, 2008, p. 100) podendo ela ser, dentre outros aspectos, participante, cujo conceito remete a "técnica pela qual se chega ao conhecimento da vida de um grupo a partir do interior dele mesmo" (GIL, 2008, p. 103), podendo ser ela natural, quando o pesquisador pertence ao grupo objeto de estudo, ou artificial, quando ele se insere, com o objetivo de realizar a sua intervenção.

\section{AS ORGANIZAÇÕES SOB A LUZ DOS REFERENCIAIS ESTUDADOS}

\subsection{Estratégia Organizacional}

No tocante à estratégia organizacional, evidencia-se a importância dos objetivos, das metas econômicas e também do planejamento estratégico em uma cooperativa, pois o bom andamento do empreendimento está fortemente condicionado à aplicação dessas ferramentas. De forma consistente, Ignácio (2008) atribui ao tema "gestão e planejamento" o adjetivo de condicionante para a sobrevivência das organizações dos agricultores nos mercados em que se inserem. Ademais, para Chiavenato (2003), planejar é o primeiro passo para quem ousa constituir uma organização de sucesso.

De acordo com o entendimento de Asaf Neto (2007) e Bialoskorski Neto (2006), as cooperativas estão inseridas em um ambiente competitivo. Por mais que as cooperativas adeptas da economia solidária não façam parte de uma rede de mercado complexa, cuja competição seja assoberbada, a definição de metas econômicas, com objetivos comerciais definidos, é um fator considerável para que se garanta, pelo menos, o mínimo necessário à prestação de serviços ou fornecimento de produtos aos cooperados e clientes.

Partindo desses pressupostos e tendo por base as informações sistematizadas dos questionários aplicados nas cooperativas (Quadro 1), percebe-se que, em uma parte das cooperativas (12/25), não existem objetivos econômicos e comerciais definidos, bem como não existem definições de metas econômicas, financeiras e comerciais $(17 / 25)$.

Quadro 1. Hierarquização dos limites e das potencialidades na subárea estratégia organizacional.

Table 2. Limits and potentialities hierarchy in organizational strategy subarea.

\begin{tabular}{|c|c|c|c|}
\hline \multicolumn{4}{|c|}{ GO1-Estratégia Organizacional } \\
\hline \multicolumn{2}{|l|}{ Limites $/ \mathrm{n}^{\circ}$ de cooperativas } & \multicolumn{2}{|c|}{$\begin{array}{c}\text { Potencialidades } / \mathrm{n}^{\circ} \mathrm{de} \\
\text { cooperativas }\end{array}$} \\
\hline $\begin{array}{l}\text { NÃO elabora, monitora e } \\
\text { executa } \\
\text { Estratégico }\end{array}$ & 20 & \multirow{6}{*}{$\begin{array}{l}\text { A visão de } \\
\text { negócios explora as } \\
\text { oportunidades de } \\
\text { mercado para a } \\
\text { agricultura familiar }\end{array}$} & \multirow{6}{*}{11} \\
\hline $\begin{array}{l}\text { NÃO possui metas } \\
\text { econômicas, financeiras e } \\
\text { comerciais definidas }\end{array}$ & 17 & & \\
\hline $\begin{array}{l}\text { A missão não contempla o } \\
\text { desenvolvimento sustentável }\end{array}$ & 14 & & \\
\hline NÃO possui visão definida & 13 & & \\
\hline $\begin{array}{lrr}\text { NÃO possui } & \text { objetivos } \\
\text { econômicos } & \text { e } \\
\text { definidos } & & \\
\text { comerciais }\end{array}$ & 12 & & \\
\hline NÃO possui missão definida & 12 & & \\
\hline
\end{tabular}

Fonte: Pesquisa (2014), organizado pelos autores.

Outrossim, Bilibio (2009) reforça a tese de que o planejamento estratégico pode ser definido como o processo pelo qual a empresa se mobiliza para garantir o seu sucesso, bem como de construir o seu futuro. O planejamento estratégico é um processo vivo, dinâmico, e deve "aglutinar forças e mobilizar a empresa como um todo, em direção ao sucesso, mas, planejar não é prever ou adivinhar o futuro, mas sim construí-lo" (BILIBIO, 2009, p. 23). Ao se apropriar de tais concepções, confere-se ao planejamento estratégico um papel imperativo para o desenvolvimento sustentável das cooperativas, sejam elas do agronegócio, da agricultura familiar, da economia solidária ou de qualquer outro conceito aglutinador.

Em 20 das 25 cooperativas estudadas, constatou-se a não operacionalização de um planejamento estratégico. Contudo, salienta-se que além dessas 20, somam-se 2 que declaravam trabalhar parcialmente com planejamento estratégico e 1 cuja resposta foi não se aplica. Porém, sem a pretensão de adentrar nesse caso, a resposta não se aplica constitui em grande equívoco de interpretação, por parte dos gestores, do que é um planejamento estratégico, e, nesse sentido, poder-se-ia somar ao conjunto de cooperativas que não atua com essa ferramenta.

Isso posto, considerando o planejamento estratégico o ponto central da Estratégia Organizacional, pode-se constatar que as cooperativas da agricultura familiar abordadas neste estudo carecem de empenho de seus gestores, colaboradores e parceiros para que supram essa lacuna, pois o planejamento e a estratégia são pontos fundamentais para a sobrevivência ou a evolução destas organizações.

Contudo, não cabe afirmar que apenas as duas cooperativas que elaboram, monitoram e executam o planejamento estratégico logram êxito em se manterem firmes no mercado, não obstante, sob a lógica dos autores que defendem a importância do planejamento, elas possuam mais chances de sobreviver e permanecer ativas em seus propósitos.

Por fim, é relevante ressaltar a questão que teve o melhor desempenho dentro da subárea Estratégia Organizacional. De 
acordo com os questionários, em 11 das 25 cooperativas os mercados disponíveis para a agricultura familiar são explorados. Também pode-se referenciar que, em 04 das 25 cooperativas, a resposta afirmada para esse item foi parcial, ou seja, a cooperativa está explorando essa oportunidade, porém ainda não plena, podendo aprimorá-lo.

Vale citar que, constituem oportunidades para a agricultura familiar o "Programa Nacional de Alimentação Escolar" e o "Programa de Aquisição de Alimentos". Tendo por base os dados de comercialização obtidos pelo projeto "Mais Gestão", em 2012, as 25 cooperativas registraram uma comercialização de $\mathrm{R} \$ 22.678 .029,15$ - sendo que $\mathrm{R} \$ 3.296 .594,74$ foi comercializado nos programas institucionais, ou seja, apenas $14,54 \%$ do montante total comercializado pelas cooperativas foi para esses programas, existindo uma grande margem para crescimento.

\subsection{Estrutura Organizacional}

No que diz respeito à Estrutura Organizacional, as questões abordam temas como procedimentos operacionais padronizados, diferenciação entre as áreas de atuação dentro da cooperativa e sobre a existência de organograma, o qual defina, de maneira clara, a autoridade e a responsabilidade dentro da cooperativa. Nota-se que, no universo pesquisado, a maior parte das cooperativas não sinalizou a disposição de procedimentos e manuais com instruções operacionais (Quadro 2).

Quadro 2. Hierarquização dos limites e das potencialidades na subárea estrutura organizacional.

Table 2. Limits and potentialities hierarchy in organizational structure subarea.

\begin{tabular}{|c|c|c|}
\hline \multicolumn{3}{|c|}{ GO2-Estrutura Organizacional } \\
\hline Limites $/ \mathrm{n}^{\circ}$ de cooperativas & & $\begin{array}{l}\text { Potencialidades } / \mathrm{n}^{\circ} \mathrm{de} \\
\text { cooperativas }\end{array}$ \\
\hline $\begin{array}{l}\text { NÃO dispõe de procedimentos e } \\
\text { manuais com instruções } \\
\text { operacionais }\end{array}$ & 23 & \multirow{5}{*}{ Não observadas } \\
\hline $\begin{array}{l}\text { O organograma NÃO define } \\
\text { linhas de autoridade e } \\
\text { responsabilidade de forma clara }\end{array}$ & 22 & \\
\hline $\begin{array}{l}\text { NÃO possui organograma geral } \\
\text { do empreendimento }\end{array}$ & 21 & \\
\hline $\begin{array}{l}\text { NÃO há diferenciação interna } \\
\text { entre as áreas produtiva, } \\
\text { comercial e gerencial }\end{array}$ & 18 & \\
\hline $\begin{array}{l}\text { NÃO dispõe de } \\
\text { funções, } \\
\text { responsabição das } \\
\text { direitos e deveres }\end{array}$ & 11 & \\
\hline
\end{tabular}

Fonte: Pesquisa (2014), organizado pelos autores.

Como podem os cooperados ou diretores de uma cooperativa participar ativamente da gestão do empreendimento se ele não possui manuais ou procedimentos estabelecidos? A autogestão difere muito da heterogestão, sobretudo, pela dificuldade em conciliar práticas, posturas e procedimentos no coletivo. Para Singer (2013), são claros os benefícios da autogestão em comparação à heterogestão; contudo, há de se considerar a necessidade de diretrizes e normativas que conduzam o trabalho do coletivo para o objetivo comum.

Por outro lado, pode-se observar a atuação das cooperativas nos mercados, os quais são complexos e demandam padrões e procedimentos. A atuação das cooperativas nos mercados, institucionais ou livres, demanda organização e procedimentos padronizados, sejam eles na produção, na coleta, na entrega ou até mesmo na hora de se apresentar as cobranças aos clientes. $\mathrm{O}$ que pode acontecer é a existência de normas que padronizam algumas atividades, porém, constatou-se, com o estudo, que, em grande parte das cooperativas, não há manuais.

Além disso, outra prática condicionante para a gestão organizacional das cooperativas é promover o acesso dos agricultores cooperados à estrutura da cooperativa, bem como o diálogo destes com os gestores e uma das maneiras pelo qual esse acesso e diálogo podem ser promovidos é pela determinação de dias específicos para atendimento dos gestores. Tais rotinas padronizadas auxiliam na construção e sedimentação da estrutura organizacional das cooperativas.

Constatou-se ainda, que 21 cooperativas não possuíam organograma geral do empreendimento. Essa ferramenta auxilia na organização do trabalho, pois possibilita a visualização da hierarquia, responsabilidades, fluxos de informações, entre outros. Ademais, verificou-se que, em 72\% das cooperativas atendidas pelo projeto "Mais Gestão", não existe diferenciação interna entre as áreas produtivas, comerciais e gerenciais. Esse dado permite sugerir a falta de organização interna dos empreendimentos estudados. Tal situação pode ter origem no acúmulo de pessoas trabalhando, porém, sem definição de cargos, tarefas e setores, ou ainda pelo fato de poucas pessoas estarem se dedicando ao trabalho, e, havendo uma quantidade pequena de colaboradores, a diferenciação interna não se torna viável.

Em tempo, cabe referenciar a falta de descrição das funções, incluindo responsabilidades, requisitos, direitos e deveres, constatada em 11 das 25 cooperativas. A presente informação corrobora 0 exposto anteriormente sobre a dificuldade em se trabalhar com a autogestão, a participação e a colaboração de diversas pessoas em um ambiente cooperativo. Assim sendo, considerando a não existência de organograma, nem divisão de tarefas e responsabilidades, tampouco diferenciação interna entre as áreas, infere-se que a prática democrática e solidária verdadeiramente impõe um esforço adicional para os integrantes de um empreendimento solidário, pois, além de ser responsável pela sua tarefa individual, no caso das cooperativas, a produção dos produtos a serem comercializados precisam também dispor de tempo para gestão do empreendimento como um todo. Segundo Singer (2013, p. 19), o "maior inimigo da autogestão é o desinteresse dos sócios, sua recusa ao esforço adicional que a prática democrática exige".

\subsection{Avaliação e Controles estratégicos}

Com relação à subárea avaliação e controles estratégicos, o diagnóstico apontou limites, principalmente no monitoramento e avaliação dos resultados, bem como a não utilização de sistema informatizado para gerenciamento das cooperativas (Quadro 3). A primeira fragilidade é recorrente em 16 das 25 cooperativas e conota a frágil cultura do monitoramento, da avaliação, que pode ser resultado também do não planejamento, da não definição de metas e objetivos econômicos, já analisados como fragilidade na subárea estratégia organizacional.

É possível inferir que a não utilização de sistema de informação gerencial informatizado constitui outro gargalo presente para o segmento, haja vista que em 11 dos 25 
diagnósticos houve essa constatação. Tal limite pode ser considerado como algo não urgente e de pouca necessidade de encaminhamentos, principalmente por ter se apresentado em um número não muito elevado de cooperativas, sobretudo se comparado a outras subáreas mais fragilizadas e com maior impacto na gestão das cooperativas.

Quadro 3. Hierarquização dos limites e das potencialidades na subárea avaliação e controles estratégicos.

Table 3. Limits and potentialities hierarchy in evaluation and strategic controls subarea.

\begin{tabular}{|l|l|l|l|}
\hline \multicolumn{4}{|c|}{ GO3-Avaliação e Controles estratégicos } \\
\hline \multicolumn{2}{|c|}{ Limites/no de cooperativas } & \multicolumn{3}{|c|}{$\begin{array}{l}\text { Potencialidades/n de } \\
\text { cooperativas }\end{array}$} \\
\hline $\begin{array}{l}\text { NÃO monitora e avalia } \\
\text { seus resultados no } \\
\text { alcance de objetivos e } \\
\text { metas }\end{array}$ & 16 & $\begin{array}{l}\text { A direção tem o hábito de } \\
\text { apresentar } \\
\text { periodicamente relatórios } \\
\text { contábeis, financeiros e } \\
\text { administrativos }\end{array}$ & 15 \\
\hline $\begin{array}{l}\text { NÃO utiliza sistema de } \\
\text { informação gerencial } \\
\text { informatizado }\end{array}$ & 11 & $\begin{array}{l}\text { A direção se reúne } \\
\text { periodicamente com o } \\
\text { conselho fiscal fiscal é }\end{array}$ & 12 \\
\cline { 2 - 2 } & $\begin{array}{l}\text { O no } \\
\text { atuante } \\
\text { empreendimento }\end{array}$ \\
\hline
\end{tabular}

Fonte: Pesquisa (2014), organizado pelos autores.

Nota-se uma grande concentração de potencialidades nessa subárea, as quais devem ser enaltecidas, pois constituem um dos alicerces do cooperativismo. Este cenário revela um cooperativismo que busca a transparência, no qual, por meio da interação entre o conselho fiscal e a direção, relatórios são apresentados e discutidos, tendo por objetivo principal a participação de mais pessoas na gestão do empreendimento. Em 15 das 25 cooperativas, existe o hábito de a direção apresentar relatórios contábeis, financeiros e administrativos aos cooperados, atitude que pode favorecer (e muito) a prática da autogestão, pois os agricultores - estando ou não interessados em participar do empreendimento - serão informados, no mínimo, com relatórios pontuais sobre a situação do empreendimento.

Sobre a direção se reunir com o conselho fiscal, situação de suma importância para a troca de informações e a planificação dos encaminhamentos da cooperativa, contatouse que, em $48 \%$ dos casos esse momento é promovido; em $24 \%$, acontece de maneira parcial, e, em $28 \%$, não acontece. $\mathrm{O}$ não encontro do conselho fiscal com a direção, necessariamente, não caracteriza um ponto negativo em sua essência, pois o papel de fiscalizar e monitorar as contas podem ser exercidos separadamente pelo conselho fiscal, e, não havendo dúvidas, as prestações de contas podem ser aprovadas ou reprovadas. Entretanto, em $36 \%$ das cooperativas, o conselho fiscal não é atuante e esta situação constitui um agravante para a gestão das cooperativas. O papel central do conselho fiscal inclui a avaliação e o monitoramento da gestão da cooperativa, função garantida por força de Lei, conforme texto que segue:

A administração da sociedade será fiscalizada, assídua e minuciosamente, por um Conselho Fiscal constituído de 3 (três) membros efetivos e 3 (três) suplentes, todos associados eleitos anualmente pela Assembleia Geral. (BRASIL, Lei n ${ }^{\circ}$. 5.764, Art. 56)

Ademais, o conselho fiscal é um dos órgãos sociais que, inclusive pode convocar uma assembleia, caso o presidente ou a diretoria se neguem a fazê-lo (BRASIL, Lei n ${ }^{0} 5.764$, Art. $38, \S 2)$. Outrossim, a realização da assembleia geral ordinária está diretamente atrelada à atuação do conselho fiscal, haja vista que a Lei $\mathrm{n}^{0} 5.764$ determina que o primeiro ponto de pauta seja "prestação de contas dos órgãos de administração acompanhada de parecer do Conselho Fiscal, compreendendo: a) relatório da gestão; b) balanço [...]" (BRASIL, Lei n ${ }^{\circ}$ 5.764, Art. 44).

Tendo por base a sua atribuição, constata-se a importância do conselho fiscal, bem como de sua atuação autônoma e articulada com a direção da cooperativa, podendo, assim, ser enquadrado como um dos grandes trunfos do cooperativismo. Nesse sentido, mesmo tendo o diagnóstico apontado que, em $48 \%$ das cooperativas, a atuação é satisfatória, faz-se necessário caminhar para que essa realidade seja constatada em $100 \%$ das cooperativas, e que cada vez mais os conselheiros fiscais busquem se capacitar, para que exerçam com facilidade as atribuições que lhe são atribuídas, reconhecendo a complexidade e a importância delas.

\subsection{Direção e Participação}

A subárea "direção e participação" retrata minuciosamente alguns aspectos da autogestão do empreendimento cooperativo. Sobre a direção, infere-se que as organizações procuram trabalhar com gestores especialistas no negócio que desempenham, ou seja, o gestor ideal em uma cooperativa de agricultores é um agricultor. Cabe a esses profissionais da área dar as diretrizes e os rumos da organização, fazendo-se valer da estrutura administrativa como apoio (CHIAVENATO, 2003).

Tendo em vista os diagnósticos analisados, constou-se como um limite significativo, presente em 20 das 25 cooperativas a não operacionalização de estratégicas para 0 fortalecimento da participação de jovens e idosos no empreendimento (Quadro 04). Nesse sentido, cabe às cooperativas rever essa situação, haja vista que tal prática está intimamente relacionada ao ideal solidário, cooperativista, que as organizações se propõem a operar.

A negação de espaço para as pessoas idosas participarem da cooperativa, seja na produção ou na gestão, constitui um processo exclusão social, uma vez que o termo pode ser definido como "múltiplas privações resultantes da falta de oportunidades pessoais, sociais, políticas ou financeiras" (HUNTER, 2000, p. 02).

Sendo assim, uma cooperativa que fortalece a participação dos idosos e lhes abre espaço se diferencia das empresas convencionais que buscam o máximo de produtividade por colaborador e que, por vezes, discriminam as pessoas de mais idade, primando pela contratação de pessoas mais jovens, que produzem mais e custam menos, por estarem se inserindo no mercado de trabalho. No entendimento de Proença (2009), uma atitude como essa também deve ser tratada como exclusão social, pois se resume na "marginalização de indivíduos ou grupos sociais em relação àqueles que produzem, consomem, convivem e são competentes" (PROENÇA, 2009, p. 21).

Sobre a inclusão de jovens nas cooperativas, essa ação precisa ser desenvolvida e com urgência, principalmente ao se levar em consideração o potencial de inovação, de adaptação às tecnologias e, mormente, a sucessão no empreendimento.

Além disso, por mais que o diagnóstico não faça referência a este aspecto, infere-se que a inclusão das mulheres também se caracteriza como um desafio para as cooperativas, posto que, não só no meio urbano e empresarial, elas foram por 
muito tempo privadas de postos de trabalho, resignando-se apenas à produção doméstica ou no meio rural à produção de autoconsumo, quando não são apenas tratadas como cuidadoras do lar designadas ao "trabalho de criar os filhos" (SEN, 2010, p. 257).

Quadro 4. Hierarquização dos Limites e das Potencialidades na Subárea Direção e Participação

Table 4. Limits and Potentialities hierarchy in Direction and Participation subarea

\begin{tabular}{|c|c|c|c|}
\hline \multicolumn{4}{|c|}{ GO4- Direção e Participação } \\
\hline \multicolumn{2}{|c|}{ Limites $/ \mathrm{n}^{\circ}$ de cooperativas } & \multicolumn{2}{|l|}{$\begin{array}{c}\text { Potencialidades } / \mathrm{n}^{\circ} \mathrm{de} \\
\text { cooperativas }\end{array}$} \\
\hline $\begin{array}{l}\text { NÃO dispõe de } \\
\text { estratégias definidas } \\
\text { para o fortalecimento } \\
\text { da participação de } \\
\text { jovens e idosos no } \\
\text { empreendimento }\end{array}$ & 20 & $\begin{array}{l}\text { Realiza assembleias } \\
\text { anuais para prestação de } \\
\text { contas }\end{array}$ & $24^{\text {iv }}$ \\
\hline \multirow{3}{*}{$\begin{array}{l}\text { NÃO utiliza boletins, } \\
\text { folders ou outras } \\
\text { mídias }\end{array}$} & \multirow{3}{*}{14} & $\begin{array}{l}\text { A direção do } \\
\text { empreendimento mantém } \\
\text { periodicidade em suas } \\
\text { reuniões. }\end{array}$ & 18 \\
\hline & & $\begin{array}{lrr}\text { Remunera ou } & \text { viabiliza } \\
\text { financeiramente } & \text { a } \\
\text { participação } & & \text { dos } \\
\text { dirigentes } & & \text { no } \\
\text { cumprimento } & \text { de } & \text { suas } \\
\text { funções } & & \\
\end{array}$ & 13 \\
\hline & & $\begin{array}{l}\text { Além das assembleias, } \\
\text { dispõe de outros espaços } \\
\text { de participação dos } \\
\text { cooperados nas decisões } \\
\text { do empreendimento. }\end{array}$ & 12 \\
\hline
\end{tabular}

Fonte: Pesquisa (2014), organizado pelos autores.

Nesse sentido, a abertura dos mercados institucionais tem favorecido as mulheres a desempenhar um papel importante na economia das propriedades, levando em conta que os produtos demandados por esses mercados são os comumente produzidos pela agricultura familiar para a própria subsistência da família, ou seja, a mulher produz os hortifrútis e os panificados para a família, e - existindo demanda de entrega para, por exemplo, a merenda escolar - aumenta a escala da produção e fornece para esse mercado.

Em função do "papel de agente", recentemente atribuído ou conquistado pelas mulheres, faz-se necessário um novo olhar nos estudos sobre o desenvolvimento, levando em consideração que "nada atualmente é tão importante na economia política do desenvolvimento quanto um reconhecimento adequado da participação e da liderança política, econômica e social das mulheres" (SEN, 2010, p. 263).

Contudo, há de se fortalecer a participação das mulheres não apenas na produção dos itens, mas também na gestão das cooperativas, na administração financeira das propriedades. $\mathrm{O}$ papel delas vai muito além da mão de obra e pode também auxiliar - e muito - a qualificação e a autogestão das cooperativas, pois não devem ser vistas como receptoras passivas de auxílio, e sim devem ser vistas como "agentes ativos de mudança: promotoras dinâmicas de transformações sociais que podem alterar a vida das mulheres e dos homens" (SEN, 2010, p. 246).

Esse olhar diferenciado para a situação da mulher deve ser uma constante para o homem e também um autorreconhecimento para elas próprias, pois "esse é, de fato, um aspecto crucial do desenvolvimento como liberdade" (SEN, 2010, p. 263).

$\mathrm{O}$ aspecto solidário, includente e justo que se espera das cooperativas solidárias, é proveniente do ideário cooperativo inicialmente proposto por Owen e Fourier, já que, para eles, o objetivo primeiro era o bem-estar das pessoas (LAGO, 2009). Essa postura inclusiva também é prevista no quinto princípio cooperativista, que reforça a necessidade de o processo de formação das cooperativas abrangerem também jovens e mulheres.

Ainda tendo por base o Quadro 04, nota-se que em 14 das 25 das cooperativas estudadas, não é comum o uso de boletins, folders ou outras mídias para divulgação de suas atividades e/ou resultados. Entende-se que a comunicação, tanto em ambiente interno como externo, é um item de grande importância para qualquer empreendimento, como demonstra Maximiano (2000) ao atribuir à comunicação o papel de fazer circular as informações necessárias para o bom andamento da organização. Para Desroche (2006), a comunicação eficiente em uma organização pode ser considerada um dos grandes segredos do sucesso.

O uso constante de boletins, folders, mural - e até de rede sociais - materializa uma das premissas da autogestão, a circulação das informações. É nesse sentido que Singer (2013) preconiza a comunicação e a troca de informações, para que os sócios de uma cooperativa se mantenham informados. Sendo assim, a comunicação e a troca de informações constituem pilares da autogestão e faz-se fundamental promover ações que apoiem as cooperativas no cumprimento desses desígnios.

O papel da comunicação se escancara ao reconhecer a economia solidária como uma autoconstrução, ou seja, os adeptos do movimento - ao conhecerem e entenderem os seus princípios - tornam-se veículos para disseminá-los, pois, para Singer (2013), construção da economia solidária depende das pessoas que são adeptas a vivê-la, "[...] de sua disposição de aprender e experimentar, de sua adesão aos princípios da solidariedade, da igualdade e da democracia e de sua disposição de seguir estes princípios na vida cotidiana." (SINGER, 2013, p. 112).

Nesse sentido, de aprender e experimentar, a comunicação interna, aliada a formação, pode contribuir muito para a propagação do ideário cooperativista solidário.

Tendo como foco a comunicação externa, ou seja, a comunicação que um empreendimento solidário prospecta para o mercado, ressalta-se que o consumo solidário pressupõe um consumidor consciente, que, ao adquirir tais produtos, está colaborando com o bem-estar da coletividade envolvida nos processos de produção, beneficiamento e comercialização. Assim, a comunicação para o mercado deve estar presente no dia a dia de um empreendimento solidário, haja vista que a comercialização para "não integrantes do movimento" fortalece e gera mais oportunidades para a economia solidária. Por conseguinte, o ato de vender deve ser, na medida do possível, uma ação educativa.

Ainda em se tratando da subárea Direção e Participação, constatou-se que, no tocante à realização de assembleia anual, em 24 cooperativas, a resposta foi positiva. Constitui uma dúvida plausível de investigação posterior o fato de que, em 1 cooperativa, não consta a realização de assembleia anual, haja vista que a realização é preconizada pela Lei Geral do Cooperativismo, em diversos artigos, claramente orientada 
para acontecer anualmente, ainda entre os três primeiros meses de exercício (BRASIL, Lei no 5.764, Art. 44).

Em conclusão, afirma-se que a situação das cooperativas abordadas neste estudo é satisfatória no que se refere à realização de assembleia anual, porém, não é sabido se essas assembleias cumprem o papel que lhes é estabelecido por lei, tendo por base o texto que segue:

A Assembleia Geral dos associados é o órgão supremo da sociedade, dentro dos limites legais e estatutários, tendo poderes para decidir os negócios relativos ao objeto da sociedade e tomar as resoluções convenientes ao desenvolvimento e defesa dessa, e suas deliberações vinculam a todos, ainda que ausentes ou discordantes. (BRASIL, Lei $n^{\circ} 5.764$, Art. 38)

Além da Assembleia Geral Ordinária, a qual, por força de lei, deve ser realizada anualmente, existem outros espaços pelos quais a cooperativa pode apoiar a participação dos cooperados, seja por meio de Assembleias Extraordinárias, reuniões, comitês, pré-assembleias ou outros. Em $48 \%$ das cooperativas avaliadas, a direção articula outros momentos para que os cooperados participem.

A disponibilidade de outros espaços para a participação dos cooperados pode ser considerada uma potencialidade, porém não se pode deixar de lado o percentual de $40 \%$ de cooperativas que não promove esses espaços alternativos. Sendo assim, acredita-se que seja necessário aperfeiçoar essa potencialidade nas que já o realizam e também trabalhar no intuito de promovê-los nas que ainda não o realizam, pois se constata que a autogestão e a participação não são, naturalmente, promovidas em favor da heterogestão, e isso não seria diferente no cooperativismo. Segundo Singer (2013, p. 21), "aprende-se a obedecer e temer os 'superiores' desde os bancos escolares, num processo educativo que prossegue a vida inteira".

Por fim, ressaltam-se outras duas potencialidades na subárea Direção e Participação. A periodicidade em reuniões da direção das cooperativas, em 18 casos de 25, demonstrando que, em grande parte, a prática da discussão e das decisões coletivas impera. Outro feito considerável é a possibilidade das cooperativas em viabilizar financeiramente a participação dos diretores no exercício de suas funções. Essa prática foi constada em 13 das 25 cooperativas analisadas e demonstra o reconhecimento da importância do papel dos diretores na gestão dos empreendimentos. Porém, tal informação não serve para avaliar o envolvimento da direção com os rumos da cooperativa, pois, em alguns casos, os diretores podem não demandar tal ajuda financeira e, em outros, mesmo havendo necessidade, a cooperativa pode não ter fundos ou conhecimentos contábeis para efetuar tal auxílio.

\subsection{Organização do Quadro Social}

$\mathrm{Na}$ última seção da área Gestão Organizacional, denominada organização do quadro social, o maior dos limites pode ser considerado a ausência de departamento ou setor responsável pelo relacionamento com os cooperados. Tal debilidade foi constatada em 22 das 25 cooperativas tomadas neste estudo (Quadro 5).

Um ponto central da autogestão, a participação dos cooperados, deve ser alvo de constantes esforços por parte da direção da cooperativa, buscando sempre o bom relacionamento com os mesmos, discutindo os interesses individuais de cada um, mas sem deixar de lado os interesses da sociedade, estabelecido na missão, visão e valores da instituição.

Quadro 5. Hierarquização dos limites e das potencialidades na subárea organização do quadro social.

Table 5. Limits and potentialities hierarchy in organization of membership base subarea.

\begin{tabular}{|c|c|c|c|}
\hline \multicolumn{4}{|c|}{ GO5- Organização do Quadro Social } \\
\hline \multicolumn{2}{|c|}{ Limites $/ \mathrm{n}^{\circ}$ de cooperativas } & \multicolumn{2}{|c|}{$\begin{array}{c}\text { Potencialidades } / \mathrm{n}^{\circ} \mathrm{de} \\
\text { cooperativas }\end{array}$} \\
\hline $\begin{array}{llr}\text { NÃO possui } & \text { um } \\
\text { departamento } & \text { (ou } & \text { setor } \\
\text { responsável) } & & \text { pelo } \\
\text { relacionamento } & \text { com } & \text { os } \\
\text { cooperados } & & \\
\end{array}$ & 22 & $\begin{array}{l}\text { Dispõe de normas } \\
\text { definidas para } \\
\text { admissão e exclusão } \\
\text { de cooperados }\end{array}$ & 15 \\
\hline $\begin{array}{l}\text { NÃO adota política de } \\
\text { formação e capacitação dos } \\
\text { cooperados }\end{array}$ & 12 & \multirow{2}{*}{$\begin{array}{ll}\text { Dispõe } & \text { de } \\
\text { mecanismos de } \\
\text { controle de produção } \\
\text { por cooperado }\end{array}$} & \multirow[b]{2}{*}{14} \\
\hline $\begin{array}{l}\text { NÃO adota política de } \\
\text { estímulo à produção e } \\
\text { produtividade junto aos } \\
\text { cooperados }\end{array}$ & 9 & & \\
\hline
\end{tabular}

Fonte: Pesquisa (2014), organizado pelos autores.

Afirmar que todas as cooperativas, desde as maiores até as menores, precisam ter um departamento estruturado para relacionamento com os cooperados é não respeitar as especificidades do tamanho do empreendimento, do tamanho do negócio e do tamanho de suas movimentações financeiras. Todavia, o relacionamento com os cooperados deve ser uma premissa básica no dia a dia de uma cooperativa, independentemente do seu tamanho, do seu ramo comercial ou de sua abrangência geográfica.

Outro gargalo, diz respeito à formação e à capacitação dos cooperados, sendo que, em 12 das 25 cooperativas, não existe uma política específica para o tema. A presente situação é exposta por Singer (2013) quando considera uma debilidade ao cooperativismo a falta de formação e, principalmente, a pouca formação para a participação social. Para o autor, é difícil aplicar as práticas de autogestão, princípio da economia solidária, se os seus integrantes ou cooperados não estão preparados, ou não costumam participar na definição dos rumos do seu próprio negócio.

Uma das principais heranças dos "socialistas utópicos" para o cooperativismo foi a preocupação com a educação. Segundo Singer (2013, p. 42), essa preocupação “deriva da ideia de que os homens são o que a educação (ou a sua falta) faz deles". Nos embriões cooperativos, muitas iniciativas primavam pela capacitação e educação não só dos cooperados, mas também de toda a sociedade.

Por outro lado, contatou-se como potencialidade nesta subárea a organização das cooperativas, no que tange à definição de normas para a admissão e exclusão dos cooperados. De acordo com a Lei 5.764/1971, art. $21 \S 2$, os estatutos sociais das cooperativas devem prever, além dos direitos e deveres dos associados, também as condições para admissão, demissão, eliminação e exclusão dos cooperados.

\section{CONSIDERAÇÕES FINAIS}

De maneira sintética, apresentam-se as potencialidades ${ }^{\vee}$ provenientes da análise dos diagnósticos das cooperativas. Em um extremo, com constância em 24 cooperativas, encontra-se a realização de assembleias anuais para prestação de contas e a existência de normas definidas para a admissão e exclusão 
de cooperados. Observa-se que essas duas potencialidades são critérios estabelecidos por lei e que, de uma maneira ou outra, as sociedades cooperativas necessitam realizar ou possuí-las.

Em outro extremo, constata-se a falta de remuneração dos diretores no exercício de suas funções em 13 cooperativas. É comum perceber que um cooperado, quando assume a função de diretor, deixa de se dedicar às suas funções produtivas, diminuindo a mão de obra em suas propriedades, gerando, em tese, um déficit econômico para a unidade de produção familiar, a qual, por perder mão de obra, ou diminui a produção ou acaba por ter custos maiores na contratação de mão de obra externa. A remuneração por si só não se caracteriza como uma maneira de substituir essa mão de obra, entretanto, algumas vezes, pode ser utilizada para isso. Em um olhar mais minucioso, percebe-se que se faz necessário, em algum momento, remunerar os gestores das cooperativas, sendo que o benefício proveniente deve ser dedicação seja colhido por todos. Tal postura, de maneira alguma, pode ser caracterizada como uma negação da economia solidária, pois, mesmo nos casos em que os dirigentes se dedicam integralmente à gestão das cooperativas, as suas retiradas "quase sempre são muito menores que os ordenados de seus congêneres em empresas capitalistas" (SINGER, 2013, p. 14).

Ao concentrar o olhar para os principais limites na área de Gestão Organizacional, nota-se com maior frequência a falta de procedimentos e manuais com instruções operacionais (em 23 cooperativas); a ausência de definições de autoridade e responsabilidade no organograma (em 22 cooperativas), ausência de organograma (em 21 cooperativas); e não possuir um departamento, ou setor, responsável pelo relacionamento com os cooperados (também em 22 cooperativas).

Com uma frequência um pouco menor, porém não menos significativa na conjuntura das cooperativas tratadas neste estudo, constatou-se que, em 20 delas, não há planejamento estratégico, tampouco estratégias para o fortalecimento da participação de jovens e idosos no seu quadro social.

Sem a pretensão de finalizar as discussões sobre o tema, apresentam-se, nos próximos parágrafos, algumas ressalvas provenientes da observação direta da pesquisa, mencionada anteriormente, bem como da interação com a literatura consultada para o estudo.

Singer (2013) relata duas experiências de cooperativismo de produção em meados de 1830 na Europa. Segundo o autor, produtores franceses e ingleses perceberam a constituição de cooperativas como uma maneira de enfrentamento ao capital. Entre as duas experiências, ele diferencia a francesa da inglesa pelo fato de que a primeira contou com um considerável financiamento estatal. Ou seja, o apoio do estado às cooperativas não é algo recente, muito menos um caso único brasileiro. Nota-se que este apoio se mantém atual e necessário, não somente para as cooperativas de produção, mas também para todas aquelas que se caracterizam como empreendimentos solidários.

A ajuda do estado será um fator importante para o movimento das cooperativas de produção, por uma série de motivos. O primeiro é que os trabalhadores não dispõem de capital nem de propriedades que pudessem oferecer como garantia para levantar capital no mercado financeiro. O segundo é que as firmas capitalistas, que concorrem com as cooperativas de produção também contam com a ajuda do Estado, sob as formas usuais de isenções fiscais e crédito favorecido. Portanto, para concorrer em condições de igualdade com estas firmas, as cooperativas de produção precisam do apoio do poder público. (SINGER, 2013, p. 93)
De acordo com o entendimento Birchall (1997), em alguns episódios na história do cooperativismo, o apoio governamental não foi suficiente para manter as cooperativas atuantes. Segundo o autor, em menos de 10 anos, as cooperativas que somavam mais de $200 \mathrm{em}$ um determinado território, reduziram-se para aproximadamente 12 . A explicação dada para tal fato é de que as cooperativas escolheram os seus integrantes sem o devido cuidado, não primando pela sua inclinação ao ato de cooperar (BIRCHAL, 1997 apud Singer, 2013).

Sobre a escolha dos cooperados, nota-se que, em muitos dos casos, não houve um trabalho de mobilização adequado com vistas à constituição de uma sociedade cooperativa. Constata-se que um dos grandes apelos para reunir agricultores foi a necessidade de se trabalhar em grupos formais para acessar determinados mercados ou para constituir escala objetivando se manterem ativos em uma cadeia produtiva cuja concorrência é muito grande.

Esse é um dos problemas do cooperativismo solidário diagnosticado e também abordado por Singer (2013) é que uma parcela significativa dos cooperadores adere ao movimento solidário apenas "para se reinserir a produção social e escapar da pobreza" (SINGER, 2013, p. 21). Nesse sentido, atribui-se esse objetivo primeiro à necessidade emergencial do sujeito em cooperar para se defender de uma mazela social, todavia, afirma ainda o autor, que, além disso, a falta de prática democrática impera nesse meio e que "muitos não chegam a apreciar as potencialidades da autogestão" (SINGER, 2013, p. 21) e apenas a aceitam (ou nem se dão conta dela) como uma exigência para poder integrar a cooperativa.

Conforme Singer (2013), esse é o retrato de uma grande expansão quantitativa do cooperativismo no Brasil e no mundo todo, mas, de acordo com o seu entendimento, qualitativamente possa ser "provável que a sua degeneração tenha se acentuado" (SINGER, 2013, p. 110). Por outro lado, a ausência de cooperativas de produção e comercialização no campo da agricultura familiar é um grande trunfo para os atravessadores, pois encontram uma base produtiva desorganizada, carente de estrutura logística e necessitando de um canal de comercialização. Esses atravessadores têm capital para comprar dos agricultores, fornecerem a logística necessária e, posteriormente, venderem para um número grande de varejistas ou exportarem os produtos com um valor agregado considerável, quando não promovem a industrialização dessas matérias-primas, retendo um valor ainda maior.

Segundo Singer (2013), buscando romper com esse cenário desfavorável, que surgiram as primeiras cooperativas agropecuárias na Dinamarca e nos Estados Unidos. De acordo com o autor, nos EUA, em 1867, já existiam 400 cooperativas atuando no setor de lácteos, processando a produção dos seus cooperados. Já na Dinamarca, em 1882, surgiu o primeiro laticínio cooperativo, e, no ano seguinte, outros 300 foram constituídos.

Não cabe dúvida de que, se hoje ainda predomina na maioria dos países a agricultura familiar, praticada em pequenas e médias propriedades, sobretudo pelos próprios proprietários e seus familiares, isso se deve aos efeitos do cooperativismo, que dão à agricultura familiar competividade e, portanto, possibilidade de resistir e se reproduzir. (SINGER, 2013, p. 87) 
Outro grande erro que pode fragilizar as práticas de autogestão nas cooperativas é, segundo Singer, proveniente da lei do menor esforço. Ou seja, as decisões que precisam ser tomadas no cotidiano, com caráter de urgência, acabam sendo encaminhadas sem consulta prévia dos cooperados. Contudo, a definição da missão, visão e valores, bem como o diálogo constante da diretoria com os cooperados pode colaborar significativamente para a gestão de empresas solidárias. Essas definições possibilitam auxílio aos gestores na tomada de decisões, sobretudo, aquelas que podem gerar conflitos entre os cooperados, ou as ações emergenciais, para as quais não existe tempo hábil de uma consulta mais ampla (SINGER, 2013).

Ao se levar em consideração a premissa de Sachs sobre a manutenção dos empreendimentos de pequeno atuantes no mercado, acesso à "tecnologia, ao crédito e ao mercado" (SACHS, 2003, p. 21) infere-se que em relação ao mercado, percebe-se que as cooperativas têm se mostrado atuantes, buscando sempre se aperfeiçoar e atender às demandas de um mercado cada vez mais exigente. Sobre o crédito, é possível constatar uma perceptível evolução, principalmente no tocante às linhas para acesso dos agricultores, contudo, há de se evoluir em algumas tratativas sobre o crédito para as cooperativas, principalmente para aquelas que não têm patrimônio necessário para conceder como garantia aos financiamentos. Por fim, sobre o acesso às tecnologias, notase que o tema ainda é pouco tratado no âmbito das cooperativas da agricultura familiar, principalmente nas abordadas neste estudo. O acesso - seja para a gestão, produção, agroindustrialização ou outro serviço - pode auxiliar (e muito) a atuação das cooperativas, mas, aparentemente faz-se necessário o apoio do estado para que as inovações sejam apropriadas por este segmento.

Contudo, no que se refere às tecnologias, mercado, crédito ou a qualquer outro acesso às cooperativas, é importante levar em consideração que o desenvolvimento precisa estar diretamente relacionado às escolhas das pessoas, ou seja, que cada cooperativa, cada cooperado possa exercer o direito de escolha, um processo de desenvolvimento para as pessoas, a fim de que o resultado chegue até elas, porém um desenvolvimento pelas pessoas, em que a população é ativa na definição dos rumos do processo ao qual serão partícipes (SACHS, 2003).

Nesse sentido, acredita-se que o desenvolvimento (tanto para as cooperativas quanto para as demais instituições voltadas ao ideário da economia solidária), não se decreta, pois ele deve ser construído por um processo pedagógico, que, em alguns casos, pode ser rápido, e em outros não (SACHS, 2009). O verdadeiro desenvolvimento se dá pela apropriação das pessoas aos processos, pela capacitação, pelo livre acesso às informações, pelo empoderamento dos atores, pelo papel de agente, pelo direito e liberdade de escolha, pela participação e pela autogestão.

\section{REFERENCIAS}

ASSAF NETO, A. Finanças corporativas e valor. São Paulo: Atlas, 2007. 722p.

BIALOSKORSKI NETO, S. Aspectos econômicos das cooperativas. Belo Horizonte: Mandamentos. 2006. 222p.

BILIBIO, C. Planejamento estratégico na empresa agrícola familiar. São Luis/MA: EDUFMA, 2009, 108p.
BRASIL. Lei n ${ }^{0} 5.764$, de 16 de dezembro de 1971. Define a Política Nacional de Cooperativismo, institui o regime jurídico das sociedades cooperativas, e dá outras providências. Disponível em: <http://www.planalto.gov.br/ccivil_03/LEIS/L5764.htm> Acesso em: 25 mai. 2018.

CHIAVENATO, I. Introdução à teoria geral da administração: uma visão abrangente da moderna administração das organizações. Rio de Janeiro: Elsevier, 2003. 634p.

DESROCHE, H. Sobre o projeto cooperativo: democracia, animação e ética. In: THIOLLENT, Michel. (Org.). Pesquisa-ação e projeto cooperativo na perspectiva de Henri Desroche. São Carlos: EdUFSCAR, 2006, p.131154.

GIL, A. C. Métodos e técnicas de pesquisa social. São Paulo: Atlas, 2008. 2009.

HUNTER, B. H. Social exclusion, social capital, and indigenous australians: measuring the social costs of unemployment, Centre for Aboriginal Economic Policy Research. Discussion Paper, n. 204, p. 1-41, 2000. Disponível em: <https://digitalcollections.anu.edu.au > Acesso em: 25 jan. 2015.

IGNÁCIO, O. M. de C. Gestão estratégica aplicada ao cooperativismo solidário: Uma alternativa de fortalecimento para os agricultores familiares. 2008, 166 f. Dissertação (Mestrado) - Universidade Federal de Goiás. Escola de Agronomia e Engenharia de Alimentos, Programa de Pós-Graduação em Agronegócio, 2008.

LAGO, A. Fatores condicionantes do desenvolvimento de relacionamentos intercooperativos no cooperativismo agropecuário. 2010. 178 f. Tese (Doutorado em Agronegócio) - Universidade Federal do Rio Grande do Sul, Porto Alegre, 2009.

MAXIMIANO, A. C. A. Introdução à Administração. 5.ed. Revisada e Ampliada. São Paulo: Atlas, 2000. 448p

PROENÇA, C. S. A exclusão social em cabo verde: uma abordagem preliminar. Lisboa, ACEP - Associação para a Cooperação entre Povos, Centros de Estudo do Instituto Superior de Economia e Gestão da Universidade Técnica de Lisboa, 2009. p. 1-73. Disponível em: http://pascal.iseg.utl.pt/ cesa/files/Doc_trabalho/76.pdf. Acesso em: 25 jan. 2015.

SACHS, I. Caminhos para o desenvolvimento sustentável. Rio de Janeiro: Garamond, 2009. 96p.

SACHS, I. Desenvolvimento includente, sustentável e sustentado. Rio de Janeiro: Garamond, 2008. 151p.

SACHS, I. Inclusão social pelo trabalho: desenvolvimento humano, trabalho decente e o futuro dos empreendedores de pequeno porte. Rio de Janeiro: Garamond, 2003. 200p.

SCORSOLINI-COMIN, F. Missão, Visão e Valores como Marcas do Discurso nas Organizações de Trabalho. PSICO, Porto Alegre, PUCRS, v. 43, n. 3, p. 325-333, jul./set. 2012.

SEN, A. Desenvolvimento como liberdade. São Paulo: Companhia das Letras, 2010. 464p.

SINGER, P. Introdução a Economia Solidária. 5.ed. São Paulo: Editora Fundação Perceu Abramo, 2013. 128p. 


\section{Gregolin et al.}

${ }^{\mathrm{i}}$ Gestão Organizacional; Gestão de Recursos Humanos; Finanças e Custos; Comercialização e Marketing; Gestão Industrial e Gestão Ambiental.

ii Para se realizar a classificação dos limites e potencialidade, levouse em consideração as respostas encontradas nas 39 questões que compõem as 05 subáreas da área Gestão Organizacional. Classificaram-se como limites as questões cujo quantitativo de respostas não fosse maior do que a soma das respostas sim e parcial, ao passo que classificou-se como potencialidade as questões cujo quantitativo de respostas sim fosse maior do que a soma de respostas não e parcial.

iii Este trabalho tem por base a Dissertação apresentada pelo primeiro autor ao Programa de Pós-Graduação em Desenvolvimento Rural Sustentável da UNIOESTE, sob o título: Dagnóstico de gestão em Cooperativas da Agricultura Familiar no estado do Paraná: limites e potencialidades em um modelo solidário e democrático, e se relaciona diretamente ao segundo e terceiro objetivos específicos, respectivamente: Pormenorizar a situação da gestão de uma das áreas do diagnóstico onde prevaleçam limitações; e Hierarquizar os limites e as potencialidades dessa área de Gestão.

iv Levando em consideração que a realização da Assembleia Gera Anual é um ato previsto no Artigo 44 da Lei Geral das Cooperativas, $\mathrm{n}^{0} 5.764$ de 16 de Dezembro de 1971, tal informação despertou curiosidade, a qual levou a busca da origem deste número diferente do total das cooperativas tratadas. A partir da busca foi possível entender que uma das 25 cooperativas, na ocasião do diagnóstico, não havia completado seu primeiro ano de atuação, logo, ainda não tinha realizado assembleia anual.

${ }^{v}$ Realiza assembleias anuais para prestação de contas e Dispõe de normas definidas para admissão e exclusão de cooperados (24/25); A direção do empreendimento mantém periodicidade em suas reuniões (18/25); A direção tem o hábito de apresentar periodicamente relatórios contábeis, financeiros e administrativos (15/25); Dispõe de mecanismos de controle de produção por cooperado (14/25) e Remunera ou viabiliza financeiramente a participação dos dirigentes no cumprimento de suas funções (13/25). 